\title{
An Assessment of Physicians' Knowledge of and Attitudes Toward the Near-Death Experience
}

\author{
Linda Hutton Moore, R.N., M.S.N., C.C.R.N. \\ Baptist Memorial Hospital System, San Antonio, TX
}

\begin{abstract}
The purpose of this study was to investigate physicians' knowledge of and attitudes toward near-death experiences (NDEs). The study population consisted of 143 staff physicians in the Baptist Memorial Hospital System. Participants completed by mail a modified version of Thornburg's (1988) Near-Death Phenomena Knowledge and Attitudes Questionnaire. Less than one-fourth of the physicians had a well-grounded knowledge base regarding NDEs, while two-thirds had a positive attitude toward NDEs. These data suggest the need for inservice programs for medical and nursing staff regarding near-death phenomena. Further studies assessing physicians' knowledge of and attitudes toward NDEs are recommended utilizing a larger population from a wider geographical region.
\end{abstract}

The near-death experience (NDE), which some refer to as a spiritual event, may occur to a patient who has experienced a close encounter with death (Greyson, 1983b). This experience has significant implications for health care professionals who provide the direct and immediate care to those patients and their families (Moody, 1975; Ring, 1984). As critically ill patients and their families perceive the physician as the lifeline to successful recovery, an exploration of physicians' knowledge of and attitudes toward the NDE is warranted.

Linda Hutton Moore, R.N., M.S.N., C.C.R.N., is a clinical staff nurse in the Medical Intensive Care Unit of the Baptist Memorial Hospital System in San Antonio, Texas. The Baptist Memorial Hospital is acknowledged for providing the majority of the funding for this project. Reprint requests should be addressed to Ms. Moore at the Baptist Memorial Hospital System, Attention: MICU Department, 111 Dallas Street, San Antonio, TX 78212. 
Regardless of the exact nature of the NDE, health care professionals must prepare to provide holistic care to patients who have these experiences.

The term "near-death experience" was initially coined by Raymond Moody (1975). Through his years of research in exploration of this phenomenon, Moody uncovered the components of the NDE through interviews of those having experienced it. Some of the more important elements he identified included (1) indescribable knowledge, or a loss of words to describe the experience; (2) hearing of one's death either from the physician or a significant other; (3) a peaceful feeling felt by the individual experiencing the NDE; (4) unusual sounds heard at the time of death or directly preceding death; (5) out-of-body experiences; (6) the tunnel, which has been described as a dimensional space in which the patient travels toward a brilliant light; (7) beings of light, who may be identified by the experiencer as deceased friends or relatives; (8) meeting a supreme being, which those experiencers with a religious background identify as God; (9) the life review, a panoramic view of one's life; (10) the border or point of no return; and (11) telling others, sometimes reluctantly for fear of being labeled as confused or hallucinating (Moody and Perry, 1988).

According to Moody (1975), the presence of one or more of the above components being reported by a patient may point toward the occurrence of a near-death experience. Bruce Greyson (1983a) also described components of NDEs in 67 individuals who reported at least one experience that consisted of the components described by Moody. Further, Michael Sabom (1982) conducted a study among 107 persons who had a close encounter with death, 70 percent of whom were cardiac arrest patients. His results revealed that about 40 percent of patients interviewed reported NDEs that contained at least ten components of the NDE as identified by Moody.

Advances in medical technology have provided a way for great numbers of critically ill patients to be resuscitated, many of whom experience NDEs (Hammond, 1989). Revived patients are increasingly reporting NDEs following their close encounters with death. It has become apparent that physicians and other health care professionals providing care for such patients need adequate knowledge and evaluation of their attitudes toward the NDE in order to help these patients deal with their close encounter with death and their emotional and spiritual feelings regarding their NDE.

Literature regarding studies that assessed knowledge and attitudes of health care professionals toward the NDE is limited. There have 
been three studies that focused on various nursing specialties' attitudes toward NDE (Barnett, 1991; Oakes, 1981; Thornburg, 1988); one study that assessed psychologists' knowledge of and attitudes toward the NDE (Walker and Russell, 1989); and two studies to investigate the knowledge and attitudes of clergy regarding the NDE (Royse, 1985; Bechtel, Chen, Pierce, and Walker, 1992).

There has been no study that assessed physicians' knowledge of and attitudes toward near-death experiences. Thus, as this study was the first to explore this topic, this research investigation was primarily descriptive in nature.

\section{Method}

\section{Subjects and Instrument}

The study population consisted of all 1,275 staff physicians caring for patients in the Baptist Memorial Hospital System in San Antonio, Texas.

The research instrument was a two-part questionnaire. The first part was developed by myself and identified demographic information about the physician, including (1) gender, (2) age, (3) medical specialty, (4) religious preference, (5) experience working with a patient who reported an NDE, (6) an indication of whether or not the physician had personally undergone an NDE, and (7) whether or not the physician thought medical staff should discuss NDEs with their patients who have had a close brush with death.

The second part of the questionnaire was a modified version of the Near-Death Phenomena Knowledge and Attitudes Questionnaire (Thornburg, 1988), which assesses attitude and knowledge level. Prior to utilizing this questionnaire, permission was obtained from its author, Nina Thornburg, to modify her instrument by shortening it and substituting the word "physician" for "nurse" where appropriate. Thornburg performed a varimax rotation on the individual questionnaire items to set reliable correlational levels. Each item utilized in this study to assess physicians' knowledge of and attitudes toward NDEs had a correlation coefficient of greater than .51 with its respective factor. The knowledge component of this questionnaire consisted of 15 true/false/undecided items, while the attitude component consisted of 25 Likert scale items. 


\section{Procedure}

Prior to conducting this study, approval was obtained from the Baptist Memorial Hospital System Nursing Research Committee and from its Ethics Committee. Data were collected by mail survey, which consisted of a detailed cover letter explaining the purpose of the survey and a questionnaire. Approximately three weeks after the initial cover letter and questionnaire were mailed out, a follow-up reminder letter was sent to each of the 1,275 physicians.

\section{Results}

\section{Demographics}

Of the 1,275 questionnaires mailed to staff physicians, 170 were returned, of which 143 were completed in their entirety, for an 11 percent response rate.

The majority of the physicians who completed the questionnaire were male (127 respondents, or 88 percent). The average age of the 143 respondents was 45 years, with a range from 29 to 77 years. Of 20 medical specialties represented on the medical staff, the greatest number of responses came from family practitioners $(n=23)$, surgeons $(n=20)$, internists $(n=14)$, and emergency physicians $(n=11)$. The majority of respondents described their religious preference as Protestant ( $\mathrm{n}=74$, or 52 percent); 45 respondents ( 31 percent) described themselves as Roman Catholic, and the remaining 24 (17 percent) as having some other religious faith or no religious preference.

Over half of physicians responding ( $n=73$, or 51 percent)reported that they had cared for a patient who had had an NDE. Further, of the 143 respondents, 18 (13 percent) reported having had an NDE themselves.

\section{Knowledge}

For the 15-item knowledge component, a score of 11 or greater represented a well-grounded knowledge base about NDEs. Using that criterion, 23 of the study participants (16 percent) were found to be 
adequately knowledgeable about NDEs. The mean score for all 143 participants was $7.4($ S.D. $=3.2$ ), with a range from 0 to 14 .

The majority of physicians responding believed that coded patients can accurately describe their resuscitation, and most respondents believed that NDEs are not triggered by medication. The majority of physicians were undecided as to whether NDEs are a defense mechanism against the threat of dying; but most indicated that people who experience an NDE have a greater appreciation for life and that the NDE affects the patient's belief in an afterlife. Table 1 summarizes knowledge responses for the 143 respondents.

\section{Attitudes}

For the 25-item 5-point Likert scale ranging from "strongly agree" to "strongly disagree," a score of 88 or greater (out of 125) indicated a positive attitude toward the NDE (that is, a mean score of 3.5 on each 5-point Likert item). Using this criterion, 93 participants (65 percent) revealed a positive attitude toward NDEs. The mean score for all respondents was 90.99 , with a range from 63 to 119 . Of the responses on the attitude component, the majority of physicians indicated that patients reporting NDEs actually have these experiences and that accounts of these experiences should be documented. Furthermore, most physicians ( $n=128$, or 90 percent) disagreed with the statement that they would not want to work with a patient who had an NDE. The majority of physicians also reported that NDE courses should be offered for health care professionals and that they would like to attend an inservice about NDEs themselves. Table 2 summarizes the 143 responses on the attitude component of the questionnaire.

\section{Discussion}

This study assessed the knowledge and attitudes of physicians toward the near-death experience. Little research has been conducted in the field of assessing health care professionals' thoughts about this phenomenon, and based on the literature review, no studies had previously assessed physicians' knowledge and attitudes.

These data revealed that physicians are aware of the near-death experience, though many may not have a well-grounded knowledge 
Table 1

Physicians' Responses on the Knowledge Component of the Questionnaire $(n=143)$

\begin{tabular}{|c|c|c|c|}
\hline Item (abbreviated wording) & $\begin{array}{l}\text { "True" } \\
\text { responses }\end{array}$ & $\begin{array}{l}\text { "False" } \\
\text { responses }\end{array}$ & $\begin{array}{l}\text { "Undecided" } \\
\text { responses }\end{array}$ \\
\hline $\begin{array}{l}\text { 1. NEs occur only near } \\
\text { death. }\end{array}$ & $63(44 \%)$ & $43(34 \%)^{*}$ & $32(22 \%)$ \\
\hline $\begin{array}{l}\text { 2. NDErs may describe a } \\
\text { choice to return to their } \\
\text { body. }\end{array}$ & $77(54 \%)^{*}$ & $16(11 \%)$ & $50(35 \%)$ \\
\hline $\begin{array}{l}\text { 3. NDErs describe their } \\
\text { experiences in similar } \\
\text { terms. }\end{array}$ & $91(64 \%)^{*}$ & $22(15 \%)$ & $30(21 \%)$ \\
\hline $\begin{array}{l}\text { 4. NDErs are eager to tell } \\
\text { others about the } \\
\text { experience. }\end{array}$ & $65(46 \%)^{*}$ & $29(20 \%)$ & $49(34 \%)$ \\
\hline $\begin{array}{l}\text { 5. Suicide-induced NDEs } \\
\text { are unpleasant. }\end{array}$ & $26(18 \%)^{*}$ & $20(14 \%)$ & $97(42 \%)$ \\
\hline $\begin{array}{l}\text { 6. NDEs are caused by } \\
\text { therapeutic drugs. }\end{array}$ & $1(1 \%)$ & $82(57 \%)^{*}$ & $60(42 \%)$ \\
\hline $\begin{array}{l}\text { 7. NDEs are a defense } \\
\text { against the anxiety of } \\
\text { dying. }\end{array}$ & $18(13 \%)$ & $49(34 \%)^{*}$ & $76(53 \%)$ \\
\hline $\begin{array}{l}\text { 8. Patients are accurately } \\
\text { able to describe their } \\
\text { resuscitation. }\end{array}$ & $101(71 \%)^{*}$ & $8(6 \%)$ & $34(23 \%)$ \\
\hline $\begin{array}{l}\text { 9. Cross-cultural NDEs } \\
\text { show significant } \\
\text { differences. }\end{array}$ & $33(23 \%)$ & $47(33 \%)^{*}$ & $63(44 \%)$ \\
\hline
\end{tabular}


Table 1 (continued)

\begin{tabular}{lccc}
\hline Item (abbreviated wording) & $\begin{array}{c}\text { "True" } \\
\text { responses }\end{array}$ & $\begin{array}{c}\text { "False" } \\
\text { responses }\end{array}$ & $\begin{array}{c}\text { "Undecided" } \\
\text { responses }\end{array}$ \\
\hline $\begin{array}{l}\text { 10. Over } 80 \% \text { of NDErs } \\
\text { show greater } \\
\text { appreciation of life. }\end{array}$ & $99(69 \%)^{*}$ & $4(3 \%)$ & $40(28 \%)$ \\
$\begin{array}{l}\text { 11. NDErs attend church } \\
\text { more often after the }\end{array}$ & $50(35 \%)$ & $7(5 \%)^{*}$ & $86(60 \%)$ \\
$\begin{array}{l}\text { NDE. } \\
\text { 12. NDErs have difficulty } \\
\text { describing their } \\
\text { experiences. }\end{array}$ & $66(46 \%)^{*}$ & $40(28 \%)$ & $37(26 \%)$ \\
$\begin{array}{l}\text { 13. NDEs are described as } \\
\text { peaceful, without pain. }\end{array}$ & $111(78 \%)^{*}$ & $5(3 \%)$ & $27(19 \%)$ \\
$\begin{array}{l}\text { 14. The impact of NDEs is } \\
\text { to increase the suicide } \\
\text { rate. }\end{array}$ & $1(1 \%)$ & $106(74 \%)^{*}$ & $36(25 \%)$ \\
$\begin{array}{l}\text { 15. NDEs affect a patient's } \\
\text { belief in an afterlife. }\end{array}$ & $83(58 \%)^{*}$ & $7(5 \%)$ & $53(37 \%)$ \\
\hline *Correct response & & & \\
\hline
\end{tabular}

${ }^{*}$ Correct response

base. The majority of physicians have a positive attitude toward this phenomenon and would like to learn more about it through inservices. These physicians also believed that nursing staff would benefit from learning more about NDEs as well.

As health care professionals, we must all provide our patients with our openness to accept what they have seen, heard, or felt during their close encounter with death. Diane Corcoran (1988) suggested several ways to accomplish this: first, health care professionals must search their own inner self to discover what their attitude toward the NDE is; second, they must try not to be judgmental toward the NDEr, allowing him or her to verbalize what happened during the encounter with death; and most importantly, they should maintain 


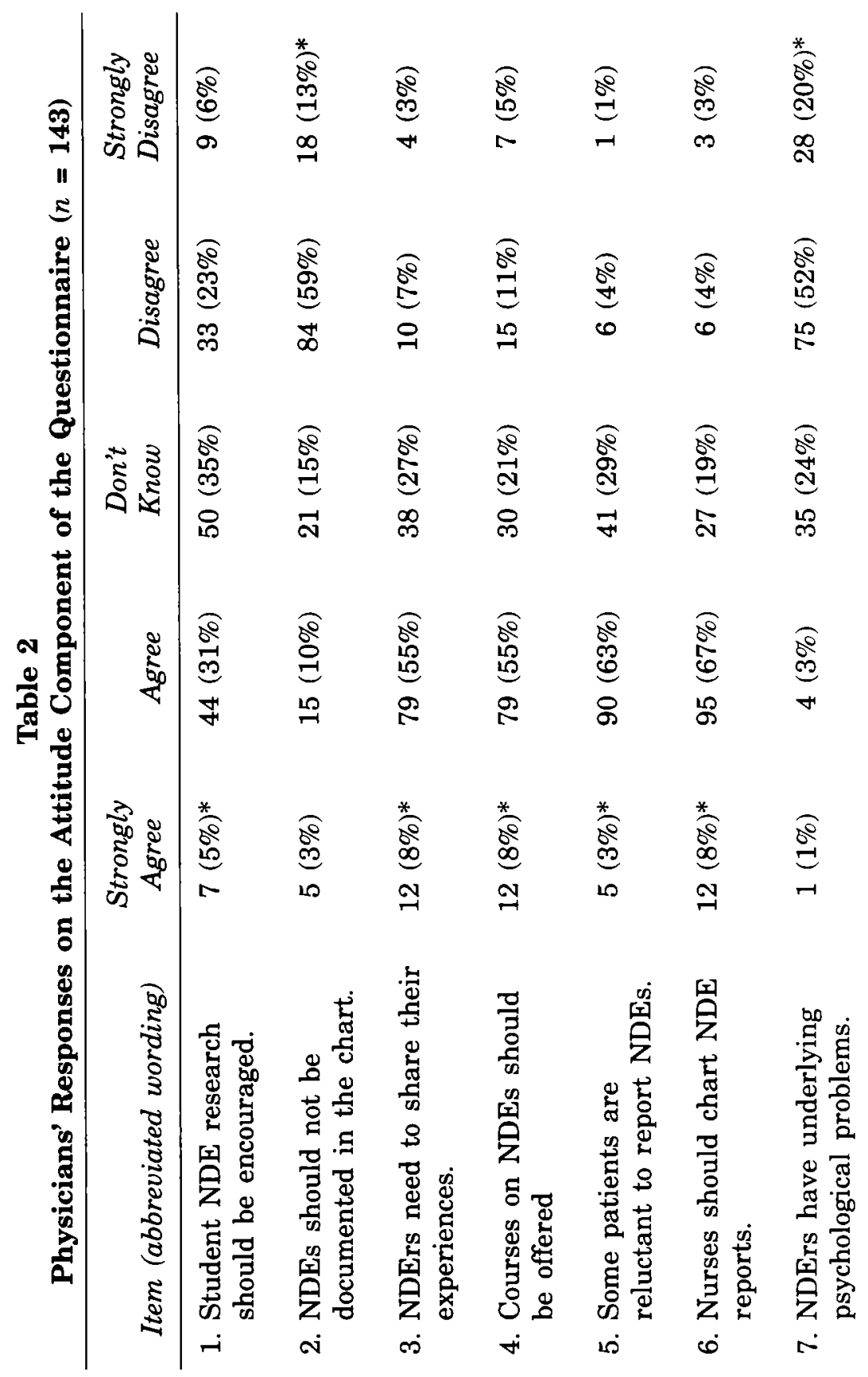




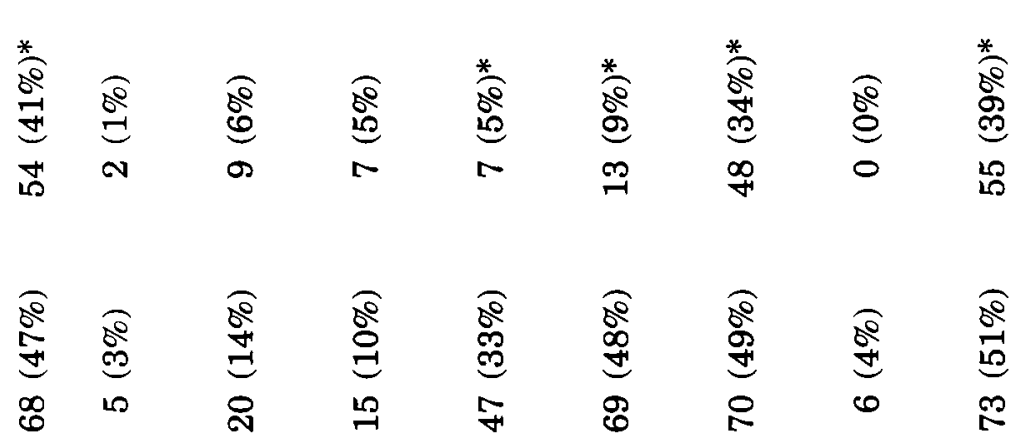

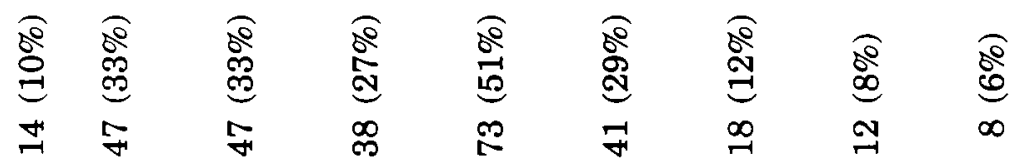

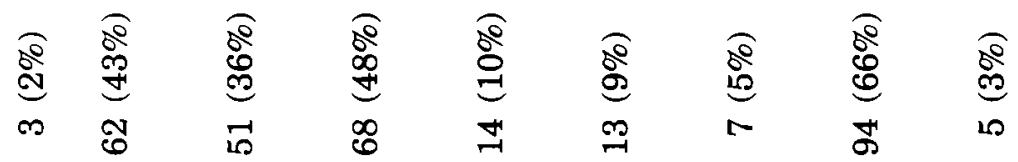

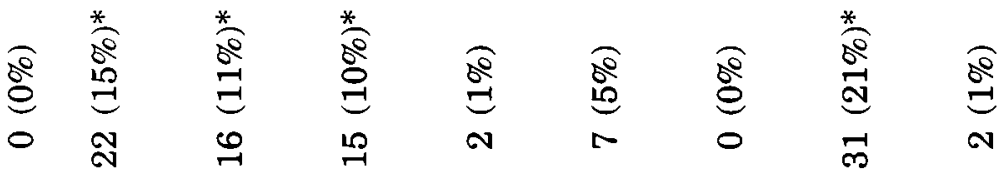

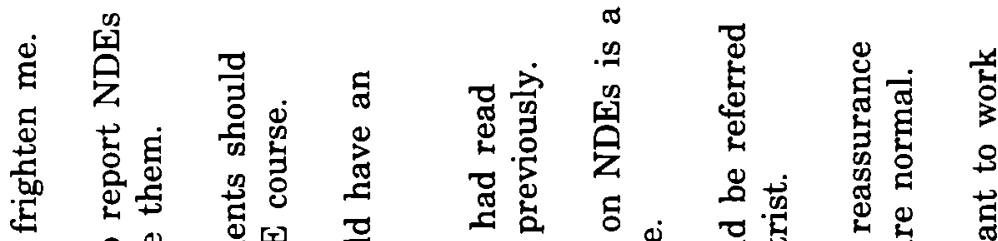

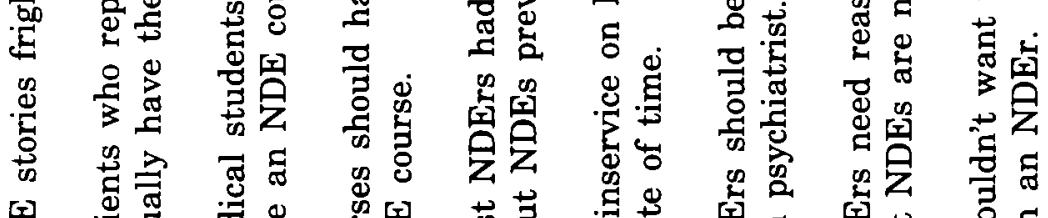

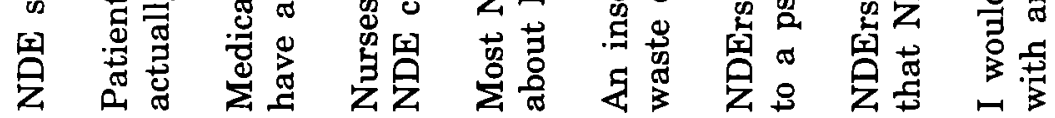

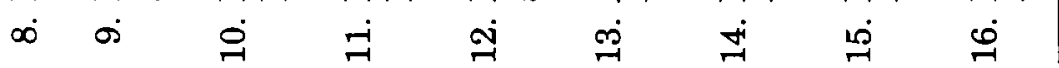




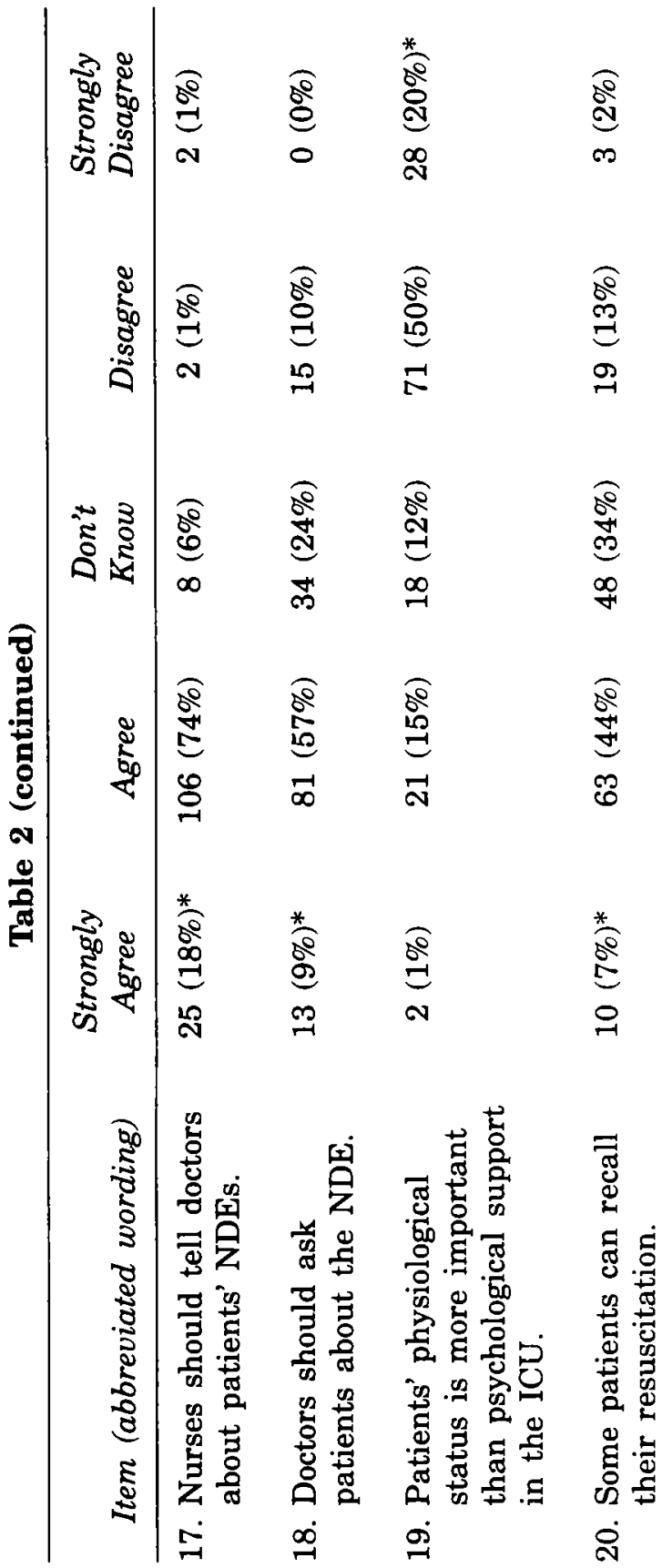




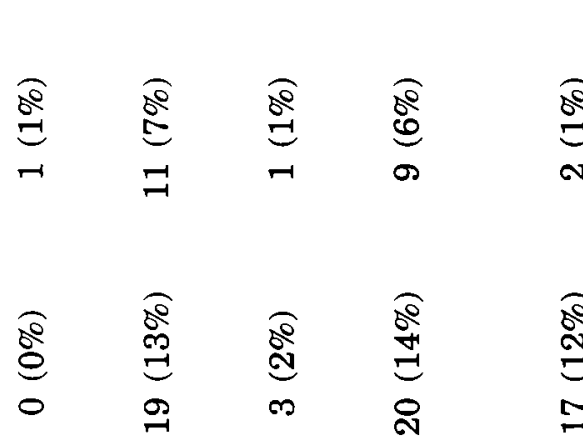

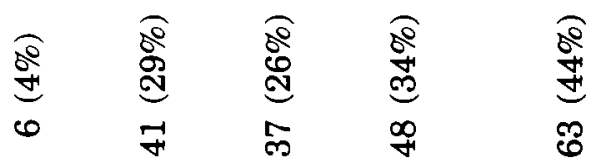

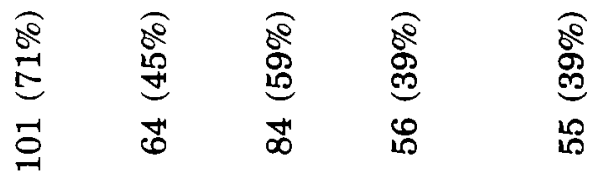

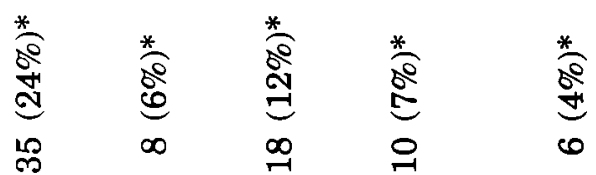

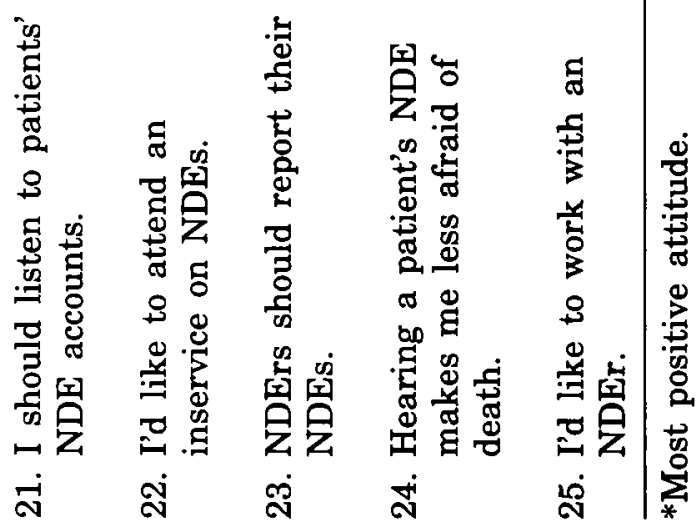


close human touch with their patients, especially during the initial period after resuscitation.

An obvious limitation to this study was the return of only 11 percent of the questionnaires from those physicians surveyed. This low response rate could have been due to a number of factors, including time limitations placed on physicians by their patient load, relative interest in the subject matter, and length of the questionnaire. This study should be replicated utilizing a larger population of physicians from a wider geographical area.

\section{References}

Barnett, L. (1991). Hospice nurses' knowledge and attitudes toward the near-death experience. Journal of Near-Death Studies, 9, 225-232.

Bechtel, L. J., Chen, A., Pierce, R. A., and Walker, B. A. (1992). Assessment of clergy knowledge and attitudes toward near-death experiences. Journal of Near-Death Studies, 10, 161-170.

Corcoran, D. (1988). Helping patients who've had near-death experiences. Nursing 88, 18(11), 34-39.

Greyson, B. (1983a). The Near-Death Experience Scale: Construction, reliability, and validity. Journal of Nervous and Mental Disease, 171, 369-375.

Greyson, B. (1983b). The psychodynamics of near-death experiences. Journal of Nervous and Mental Disease, 171, 376-381.

Hammond, R. (1989). Near-death experiences: Beyond the ordinary call. Journal of Emergency Medical Services, 14(10), 51-53.

Moody, R. A., Jr. (1975). Life after life. Covington, GA: Mockingbird Books.

Moody, R. A., Jr., and Perry, P. (1988). The light beyond. New York, NY: Bantam.

Oakes, A. (1981). Near-death events and critical care nursing. Topics of Clinical Nursing, 3(3), 61-78.

Ring, K. (1984). Heading toward omega: In search of the meaning of the near-death experience. New York, NY: Morrow.

Royse, D. (1985). The near-death experience: A survey of clergy's attitudes and knowledge. Journal of Pastoral Care, 39, 31-42.

Sabom, M. B. (1982). Recollections of death: A medical investigation. New York, NY: Harper and Row.

Thornburg, N. (1988). Development of the Near-Death Phenomena Knowledge and Attitudes Questionnaire. Journal of Near-Death Studies, 6, 223-238.

Walker, B. A., and Russell, R. D. (1989). Assessing psychologists' knowledge and attitudes toward near-death phenomena. Journal of Near-Death Studies, 8, 103-110. 